DOI: https://doi.org/10.46630/phm.12.2020.08

Snežana Ž. Petrova ${ }^{1}$

Article de recherche

Université « Saints Cyrille et Méthode » à Skopje

УДК 316.73(497.7:44)

Faculté de philologie « Blaže Koneski »²

Reçu : le 5/3/2020

Département de langues et littératures romanes

\title{
LES RELATIONS CULTURO-ÉDUCATIVES ENTRE LA MACÉDOINE DU NORD ET LA FRANCE
}

Les relations culturelles et éducatives entre l'Est et l'Ouest, plus exactement entre la Macédoine du Nord et la France sont anciennes, plus ou moins constantes, plus ou moins visibles, plus ou moins approuvées, plus ou moins légitimées ; néanmoins, celles-ci sont apposées et entretenues par des facteurs institutionnels et personnels essentiels donnant une valeur et un rayonnement à la langue et à la culture de ces deux pays.

Notre article consiste en un travail de recherche qui sera concrétisé sous forme de rapport des actuelles instances macédoniennes en France comme des françaises en Macédoine du Nord, de l'exposé de leurs services et coopérations, du témoignage de leur action et implication du point de vue culturel ou éducatif, de la présence et visibilité de la culture et langue françaises au sein même des institutions éducatives macédoniennes. Cet article aura donc pour but d'être le témoignage des immersions bilatérales entre les deux pays, mais également proposera des visées possibles ou réflexions pour une pérennisation des partenariats.

Mots-clés : relations culturelles, institutions, enseignement de la langue et culture françaises, France, Macédoine du Nord

La distinction « culturo-éducative » dans les relations entre la Macédoine du Nord et la France qui est le fondement de notre étude provient originellement de notre réflexion sur la situation comme de la recherche et de l'analyse des causes et conséquences dans lesquelles se trouve l'enseignement de la culture et de la langue françaises dans notre pays, la Macédoine du Nord. Ainsi, depuis une petite décennie, la situation en ce qui concerne l'apprentissage et l'enseignement de la langue et de la culture françaises est de plus en plus alarmante.

\footnotetext{
${ }^{1}$ snezanapetrov@me.com

${ }^{2}$ Cet article a été réalisé dans le cadre du projet Langues, littératures et cultures : politiques éducatives en fonction de la société contemporaine de la Faculté de philologie "Blaže Koneski » de l’Université « Saints Cyrille et Méthode » à Skopje.
} 
Rappelons que le français y est enseigné ${ }^{3}$ tout d'abord dans quelques jardins d'enfants ou des maternelles privés ou publics grâce à un projet de sensibilisation à la langue française, puis à l'école primaire en tant que seconde langue étrangère et cela à partir de la $6^{\mathrm{e}}$ classe. Le français est implanté dans le programme scolaire en tant que matière obligatoire, mais au choix entre différentes langues (le français, l'allemand, le russe et depuis peu l'italien), puis dans le secondaire (dans des établissements publics ou privés, en tant qu'enseignement bilingue ou classique), et finalement à l'université. Malgré cette implantation dans les différentes strates du système scolaire et malgré son histoire sur le sol macédonien et la présence d'institutions qui promeuvent la langue et la culture françaises, nous nous confrontons à une diminution d'intérêt pour son apprentissage qui évolue vers sa disparition en tant que matière dans certains établissements. Quelles sont les causes de cette diminution d'effectifs écoliers comme celui du cadre enseignant ? Pourquoi cette perte d'intérêt pour le français ? Pour pouvoir y répondre, nous devons tout d'abord présenter les acteurs des relations culturo-éducatives entre ces deux pays que sont la Macédoine du Nord et la France et surtout comprendre leurs implications en ce qui concerne l'enseignement de la langue et de la culture ${ }^{4}$.

\section{Les relations culturelles et éducatives entre la Macédoine et la France}

Les relations culturelles et éducatives entre l'Est et l'Ouest, plus exactement entre la Macédoine du Nord et la France sont anciennes, plus ou moins constantes, plus ou moins visibles, plus ou moins approuvées. Elles sont entretenues par des institutions, par des services plus ou moins visibles et plus ou moins présents dans la vie culturelle et éducative du pays qui les loge. Cependant le rapport de visualisation des immersions culturo-éducatives bilatérales entre les deux pays ne peut se faire sans comprendre les notions du substantif « culture ».

\subsection{La culture}

"La culture domine tout, elle est la condition sine qua non de notre civilisation.", constatait déjà le Général de Gaulle en 1965 lors de l'inauguration

\footnotetext{
${ }^{3}$ Nous reviendrons sur la question de l'enseignement/apprentissage du français en milieu scolaire un peu plus loin dans notre texte.

${ }^{4}$ Toutes les problématiques culturo-éducatives ne pourront pas être développées dans notre étude, car nous avons décidée de prélever uniquement ce qui a fait écho à notre expérience au risque de proposer qu'une vision partielle de la question.
} 
de la maison de la culture de Bourges ${ }^{5}$.

Concrètement, la définition de la culture est complexe et possède une diversité de sens. Maintes personnes et institutions ont essayé de la définir au mieux, que cela soit du côté français que du côté macédonien. Mais communément et d'après le dictionnaire Larousse, nous pouvons dire que la culture peut être comprise comme :

« un ensemble de pratiques, de phénomènes matériels et idéologiques qui caractérisent un groupe ethnique ou une nation, une civilisation, par opposition à un autre groupe ou à une autre nation : la culture occidentale »;

définition qui se complète en ces termes :

« dans un groupe social, [c'est un] ensemble de signes caractéristiques $\mathrm{du}$ comportement de quelqu'un (langage, gestes, vêtements, etc.) qui le différencient de quelqu'un appartenant à une autre couche sociale que lui : culture bourgeoise, ouvrière $»^{6}$.

Cependant, la définition prise comme telle n'est pas suffisamment significative et il faudrait rajouter la constatation d' " évolution du sens » qu'Emmanuel de Waresquiel, auteur de l'Avant-propos du Dictionnaire des Politiques culturelles de la France depuis 1959 ajoute : « [le sens du mot « culture »] évolue à l'aune de la montée en puissance des marchés, de la consommation, et du poids grandissant de l'économie comme de ses ramifications à l'échelle du monde » (dir. Waresquiel, 2001 : V).

Aujourd'hui, la culture, qu'elle soit française ou macédonienne, fait face à une « mondialisation »; nous entendons par là, qu'elle s'enrichit par une circulation des cultures ou sous-cultures diverses qui se sont soit déjà instaurées depuis un laps de temps suffisamment conséquent ou sont soit en cours de développement sur le territoire, qu'il s'agisse de cultures provenant d'autres pays, de ses propres régions ou empruntés à des minorités ou immigrants. Néanmoins, la culture, face à cette « mondialisation », tente plus ou moins de conserver ses propres richesses culturelles et ses propres spécificités ${ }^{7}$ en les mettant en évidence en présentiel ou sur la Toile selon une politique culturelle du pays plus ou moins bien rôdée. Et justement, la politique culturelle, comme le remarque Jean-Michel Djian, dans La Politique culturelle, la fin d'un mythe (Djian, 2005 : 9) est une singularité « française », qui définit la France en son sein comme à l'étranger et qui est conduite par un ministère et différents

\footnotetext{
5 https://www.culture.gouv.fr/60ans60dates\#/Thursday-23-July-1959-Creation-du-ministerede-la-Culture

${ }^{6} \mathrm{https}$ ://www.larousse.fr/dictionnaires/francais/culture/21072

${ }^{7}$ « La culture française est ce qu'elle est aujourd'hui grâce à la naissance de la langue française et à l'enrichissement provenant des autres cultures. Aujourd'hui, face à la mondialisation, la France tente de conserver les richesses de sa culture » in http://www.notrefrance.com/culture
} 
départements ministériels comme par de nombreuses institutions nationales, des académies, des musées nationaux etc. Mais, la politique culturelle de la Macédoine est-elle aussi visible et dynamique que la française ?

\section{La politique culturelle : France vs Macédoine}

\subsection{Les institutions en France}

Selon Milena Dragićević Šešić : « la politique culturelle fut pendant longtemps une activité réservée aux cercles fermés des gestionnaires culturels du secteur public, sous le patronage du ministère de la Culture et de l'idéologie du parti politique qu'il représente » (DRAGICEVIC ŠEŠIC 2015 : 37). Ainsi, en France, la création d'un « ministère des Affaires culturelles » a été décidé par le Général de Gaulle par décret daté du 24 juillet 1959 et rédigé par André Malraux en tant que ministre de la Culture. Il a été décrété que ce ministère soit chargé :

[...] des affaires culturelles [et aura] pour mission de rendre accessibles les œuvres capitales de l'humanité, et d'abord de la France, au plus grand nombre possible de Français, d'assurer la plus vaste audience à notre patrimoine culturel et de favoriser la création de l'art et de l'esprit qui l'enrichissent. ${ }^{8}$

Par conséquent, cette mission consiste avant tout en une " culturalisation » des Français par une prise de conscience de leurs biens culturels et donc une appropriation de leur propre patrimoine.

Puis, le texte se complète par :

«À ce titre, [le ministère] conduit [une] politique de sauvegarde, de protection et de mise en valeur du patrimoine culturel, et contribue à l'action culturelle extérieure de la France et aux actions relatives aux implantations culturelles françaises à l'étranger'.

ce qui implique une présence française à l'étranger rendue visible par des institutions et par des actions culturelles. Et comme le dit le ministre de la culture actuel, Franck Riester, dans son éditorial du dossier de presse pour la célébration des 60 ans du ministère de la Culture (1959-2019) :

«Plus généralement, notre culture est ce qui nous relie, ce qui nous rapproche, ce qui nous rassemble. En plus d'être ce ciment social, c'est un motif de fierté pour nos concitoyens, un secteur essentiel pour l'économie du pays, et un puissant vecteur d'attractivité pour nos territoires ${ }^{10} \gg$.

\footnotetext{
8 (https://www.culture.gouv.fr/60ans60dates\#/Thursday-23-July-1959-Creation-du-ministerede-la-Culture).

${ }^{9}$ Ibid.

${ }^{10} \mathrm{https}$ //www.culture.gouv.fr/Presse/Dossiers-de-presse/La-programmation-des-60-ans-du-ministere-
} 
Certes, mais il faut rappeler le fait que :

« Depuis l'après-guerre [...], le mot « culture » de son acceptation « classique » $[. .$.$] qui renvoie sur le plan des politiques culturelles [...], évolue$ vers une pluralité de sens : cultures « minoritaires », « jeunes », « locales », « d'emprunt » ou encore « multiculturalisme »» (dir. WARESQUIEL 2001 : $\mathrm{V})$.

et justement, il faut tenir compte :

« de ces glissements de sens [si l'on] veut saisir la complexité [de plus d'un] demi-siècle de politiques culturelles françaises depuis la création du ministère des Affaires culturelles en 1959 »(dir. WARESQUIEL, 2001 : V).

glissements qui, comme l'estime Waresquiel, deviendront avec le temps de véritables enjeux politiques (WARESQUIEL 2001 :V). Néanmoins, la pluralité de sens du mot «culture » et sa mise en pratique comme son développement mènera avec le temps vers des froissements de conviction, des désaccords entre acteurs culturels et les valeurs décisionnelles et de procédés imposants de l'État français, vers « une sorte de [...] désenchantement entre l'appel des cultures identitaires et l'omniprésence des « exclus » de la culture, entre la tentation de l'élitisme et le devoir de démocratie » (WARESQUIEL 2001 : VI, VII), ce que nous voyons également apparaître en Macédoine.

En ce qui concerne le ministère de la Culture macédonien, celui-ci existe en tant que tel depuis l'indépendance du pays, en 1991. Celui-ci mène une politique culturelle similaire à celle de la France et englobe également de nombreuses institutions nationales ${ }^{11}$ réparties dans le pays et particulièrement

de-la-Culture

${ }^{11}$ Le théâtre d'art dramatique, la Bibliothèque nationale universitaire « St. Clément d'Ohrid » à Skopje, la Philharmonie de la R.M.N, l'Opéra et ballet, l'Institution nationale ou l'Ensemble de danses et chants nationaux de Macédoine «Tanec », Vardar Film, le Théâtre national macédonien, le Théâtre pour enfants, le Théâtre albanais, le Théâtre turc, le Centre conservatoire - Skopje, le Musée d'art contemporain, la Galerie nationale de Macédoine, l'Agence pour film de la R.M, l'Institution nationale « Stobi gradsko », le Mémorial de mère Tereza, le Théâtre comédie, la Bibliothèque universitaire de Bitola, le Théâtre populaire de Bitola, le Centre culturel de Bitola, l'Institut et musée de Bitola, le Musée de l'alphabet albanais de Bitola, le Centre culturel « Kočo Racin » de Kičevo, le Centre culturel « Beli Mugri » de Kočani, la Bibliothèque " Grigor Prličev » d'Ohrid, le Centre culturel " Grigor Prličev » d'Ohrid, l'Institut de protection des monuments et musées d'Ohrid, le Festival d'été d'Ohrid, le Centre culturel « Marko Cepenkov de Prilep, l'Institut national pour la protection des monuments et de la culture et musées de Prilep, le Centre culturel « Braka Miladinovci » ou « les frères Miladinovci » de Struga, l'Institution nationale - Musée « Nikola Nezlobinski » de Struga, l'Institut de protection des monuments et musées de Strumica, la Bibliothèque " Kočo Racin » de Tetovo, le Centre culturel «Aco Sopov» de Štip, l'Institut de protection des monuments et musées de Štip, le Mémorial de Todor Proeski de Kruševo, l'Institut national et Musée de la lutte macédonienne de Skopje, le Centre national de conservation de Skopje, la Cinémathèque de la R.M.N., le Musée d'histoire naturelle de Macédoine. 
centralisées dans la capitale, Skopje. L'objectif de ces institutions est certes de promouvoir la culture macédonienne mais également les cultures des différents groupes ethniques que constitue sa société, de façon plus ou moins offensive selon les partis politiques au pouvoir.

\subsection{Les institutions macédoniennes en France, à Paris}

L'ambassade de Yougoslavie à Paris existe depuis 1945, plus exactement depuis l'armistice de la seconde guerre mondiale. En tant que telle, elle est l'écho de trois langues officielles (le serbo-croate, le macédonien et le slovène) ainsi que de leur culture respective. Il faut noter qu'à partir de 1945 et jusqu'à l'indépendance de la Macédoine (1991), la culture macédonienne se manifeste en France par des conférences tenues dans des universités, par des stages professionnels suivis par de nombreux ingénieurs, médecins, peintres, sculpteurs, etc. macédoniens, comme par des échanges culturels, ce qui fait qu'officiellement la culture, la langue et la civilisation macédoniennes sont bien présentes. Depuis l'indépendance du pays, et plus précisément depuis 1992, une Ambassade de la Macédoine s'est ouverte à Paris. Elle est l'une des 672 représentations étrangères en France, l'une des 169 représentations étrangères à Paris et également l'une des 102 représentations diplomatiques et consulaires de Macédoine du Nord dans le monde. Elle est à notre connaissance, en tant qu'institution, l'unique représentant institutionnel de la culture de ce pays à Paris.

Sa mission est la promotion de la culture macédonienne dans le but de rapprocher et de faire connaître les spécificités et multiplicités culturelles de ce pays. Ainsi, " par le biais de diverses activités et manifestations, l'Ambassade s'efforce de donner une visibilité internationale à la fois aux courants contemporains de l'art macédonien et à son patrimoine culturel $»^{12}$.

$\mathrm{Du}$ point de vue de l'enseignement et de l'apprentissage de la langue et de la culture macédoniennes, à notre connaissance, celui-ci s'exerce à un niveau universitaire uniquement à l'Institut national des langues et civilisations orientales (INALCO) qui d'après son site propose « [...] un enseignement supérieur complet et diversifié de la langue macédonienne et [offre] des formations diplômantes nationales: Licence, Master I et Master II, Doctorat (L.M.D.) et des diplômes d'établissement - Diplôme de langue et civilisation : DLC1, DLC2, DLC3, DLC4, qui s'adressent à des débutants ${ }^{13}$. Puis, en moindre mesure, à un niveau primaire, facultatif et complémentaire, pour les enfants de la diaspora macédonienne, d'abord à Rouen en 1973, puis à partir

\footnotetext{
${ }^{12}$ https://www.ficep.info/post/ambassade-de-la-république-de-macédoine-du-nord

${ }^{13} \mathrm{http}: / /$ www.inalco.fr/langue/macedonien
} 
du $1^{\text {er }}$ septembre 1974 à Paris ${ }^{14}$, en offrant des cours de langue et civilisation macédoniennes, une fois par semaine $(2 \times 90 \mathrm{mn})$, jusqu'à la $8^{\mathrm{e}}$ classe (1314 ans). Mais, cet engagement à but éducatif passe principalement par des Associations ou organisations franco-macédoniennes.

Cependant, il est plus qu'évident que la présence de la culture et langue macédoniennes en France est encore trop limitée et limitrophe, en admettant également que les principales activités se réalisent à Paris, par l'ambassade de Macédoine du Nord, et rarement par quelques groupes, organisations ou associations. Le ministère de la culture de Macédoine du Nord doit donc s'efforcer de donner plus de visibilité à la culture macédonienne à l'étranger et plus particulièrement en France.

\section{Les décrets en ce qui concerne les politiques culturelles entre la France et la Macédoine du Nord}

L'accord de coopération culturelle, éducative, scientifique et technique entre le gouvernement de la République française et le gouvernement macédonien est illustré par le dernier Décret en date, n 99-62 du 25 janvier 1999, signé à Paris le 29 janvier 1998 et publié au Journal officiel de la République française ${ }^{15}$. Les signataires de ce dudit Décret sont Hubert Védrine, ministre des affaires étrangères sous le gouvernement de Jacques Chirac et de Lionel Jospin en tant que premier ministre du côté français et par le ministre de la culture macédonien Slobodan Unkovski du côté macédonien. Cet accord dont la validité est prorogée par tacite reconduction de 5 ans en 5 ans est valable aujourd'hui encore.

Ce décret et surtout son annexe (ou Accord), implique que les deux parties soient convaincus de l'importance de leur «coopération dans le domaine de la culture, de l'éducation, de la technique, des sciences et des technologies » et qu'ils soient désireux de développer et de promouvoir la connaissance et la diffusion de la langue de l'autre Partie ${ }^{16}$. D'ailleurs, les principales dispositions sont inclues dans l'article 2 de ce document :

- Elles facilitent les contacts entre personnalités du monde intellectuel et artistique.

- Favorisent la coopération et les échanges entre les institutions et les milieux professionnels des deux pays (bibliothèques, éditeurs, traducteurs, libraires, auteurs).

\footnotetext{
${ }^{14}$ Ce genre d'enseignement a également été assuré dans les villes de Dieppe, Lyon, et dans la région parisienne.

${ }^{15}$ https://www.legifrance.gouv.fr/affichTexte.do?cidTexte=JORFTEXT000000575586\&catego rieLien $=\mathrm{id}$

${ }^{16} \mathrm{Ibid}$.
} 
- Favorisent également les échanges de manifestations artistiques, et toute forme de coopération entre les archives, les musées, les bibliothèques et autres institutions culturelles etc... ainsi que dans le domaine de la protection et de la préservation du patrimoine culturel. ${ }^{17}$

Ainsi que dans l'article 3 :

«Les Parties encouragent l'activité des établissements culturels existants ou qui viendraient à être ouverts sur leur territoire respectif par l'autre Partie, tels que centres culturels et de coopération, centres de documentations, bibliothèques et médiathèques, alliances françaises $[\ldots] \gg^{18}$

Cependant, nous notons que de tels centres macédoniens n'existent pas en France, mais existent bien en Macédoine.

Et finalement dans l'article 4 où il est mentionné entre autres et de façon restreinte que : « Chaque Partie encourage l'enseignement et la diffusion sur son territoire de la langue de l'autre Partie... $»^{19}$.

Certes, à Paris, l'INALCO offre un enseignement de la langue et de la culture macédoniennes, et les enfants de la diaspora peuvent suivre un enseignement primaire, de base, facultatif ou complémentaire. Mais est-ce suffisant? D'un autre côté, en Macédoine, la présence et visibilité de la culture française est beaucoup plus évidente. Peut-on parler de coopération mutuelle des deux parties?

\subsection{La décentralisation des politiques culturelles}

La coopération mutuelle des deux Parties sous-entend une décentralisation des politiques culturelles. À ce sujet, l'article 10 du Décret $n^{\circ} 99-62$ du 25 janvier 1999 porte mention :

«Les Parties souhaitent que se développent les diverses formes de la coopération décentralisée entre collectivités territoriales des deux pays dans le cadre de leur législation nationale. Ainsi nous aurons des échanges d'expérience, mise en œuvre de programmes de coopération en commun...»

Une première coopération décentralisée existe entre la ville d'Epinal et la ville de Bitola ; jumelage qui dure depuis le 2 juin 1968, soit 52 ans, et qui ne cesse de s'approfondir avec les années. Une seconde coopération est signifiée entre l'Alsace et la Macédoine dans le domaine universitaire par des échanges d'étudiants mais également au travers de l'association ALMA - Alsace Macédoine. Actions concrétisées entre autres par des activités relatives à l'œnologie et à la gastronomie, mais également par celles de l'éco-tourisme ou le tourisme de mémoire ${ }^{20}$.

\footnotetext{
${ }^{17} \mathrm{http}: / /$ www.axl.cefan.ulaval.ca/francophonie/francophonie_decret-Fr-Macedoine.htm

${ }^{18}$ Ibid.

${ }^{19}$ Ibid.

${ }^{20} \mathrm{https}$ ://mk.ambafrance.org/Visite-d-une-importante-delegation-alsacienne-en-Macedoine
} 
Finalement, depuis 2006, un programme de coopération décentralisée s'est instauré entre la Région Normandie (ou sous la nomination de Basse-Normandie à l'époque de la création) et la République de Macédoine. Ce programme est soutenu par dérogation exceptionnelle du côté français par la Région Normandie et le Ministère de l'Europe et des Affaires étrangères français et du côté macédonien par le Ministre de l'autogestion locale de la République de Macédoine et le Secrétariat d'affaires européennes de la République de Macédoine. Ce même programme est également coordonné par l'Association européenne pour la démocratie locale (ALDA) qui a publié une brochure sous le titre de La coopération décentralisée entre la région Normandie et la république de Macédoine dans laquelle elle présente et explique ses actions. Son programme a pour « objectif principal de contribuer à l'ouverture au monde des populations de ces deux territoires. Il s'agit d'une coopération innovante : une région française coopère avec un État, l'État macédonien $\gg^{21}$ qui passe par un renforcement de la gouvernance locale des deux et par la réalisation d'actions transversales portant sur le développement local et régional. Ainsi, une collaboration partenariale s'est installée entre Lokomotiva et la région de Pélagonie dont les objectifs sont listés sur le site de «La Coopération décentralisée entre la BasseNormandie et la Macédoine » et plus précisément dans le paragraphe sur l'axe de coopérations politico-culturelle ${ }^{22}$ :

- Renforcer la gouvernance locale en matière de politiques culturelles

- Favoriser les échanges interculturels, la mobilité des artistes

- Encourager le dialogue intersectoriel

- Valoriser les cultures des deux territoires

- Développer des outils de coopération culturelle sur et entre les deux territoires

- Créer des réseaux et partenariats entres structures et pôles éducatifs en matière de culture

Cette collaboration comprend également des jumelages qui sont déclinés sur le même site et relatif à tous types d'échange ${ }^{23}$ :

\subsection{Les Jumelages des villes françaises/macédoniennes}

1. Ohrid (MK) - Caen (FR)

2. Struga (MK) - Ouistreham (FR)

3. Vevcani (MK) - Hermanville-sur-Mer (FR)

4. Debar (MK) - Ifs (FR)

${ }^{21}$ http://bn-mk.org/content/développement-régional.html Relations institutionnelles - Au service de la gouvernance locale

${ }^{22} \mathrm{http} / / / \mathrm{bn}-\mathrm{mk}$. org/fr/content/axe-de-coopération-politiques-culturelles.html

${ }^{23} \mathrm{http} / / / \mathrm{bn}-\mathrm{mk}$.org/content/jumelage-des-villes-0.html 
5. Berovo (MK) - Livarot (FR)

6. Veles (MK) - Cherbourg-Octeville (FR)

7. Karposh (MK) - Fleury-Sur-Orne (FR)

Ces échanges sont dans notre cas, en tant qu'enseignants, visibles, particulièrement depuis 2014, grâce à l'établissement de coopérations dans le domaine éducatif. Ainsi, certaines écoles macédoniennes ont pu se jumeler avec des écoles françaises dans des projets du domaine de la jeunesse, de la culture, du patrimoine, du tourisme durable, et de l'environnement etc. et bénéficier d'une ouverture au monde par l'approfondissement de connaissances, de nouveaux apprentissages, collaborations et visions citoyennes.

Cependant, à part ces quelques collaborations de décentralisation, ces quelques jumelages et autres actions/acteurs qui ne sont pas ici tous et toutes énuméré(e)s (coopération linguistique, éducative et scientifique - la maternelle française (ou Jardin d'enfants francophone inauguré en 2000), qui maintenant fait partie de l'EFIS (École française internationale de Skopje inauguré en 2014 et homologué par le ministère de l'Éducation nationale français par un arrêté ministériel en date du 16 juin 2015), le Centre de réussite universitaire «Le Très-FLE» de l'AUF près l'Université " Saints Cyrille et Méthode » à Skopje, etc.), il existe aussi des coopérations dites audiovisuelles suite à une convention entre Canal France International et la télévision publique macédonienne, lesquelles à notre avis sont insuffisantes pour des raisons qui dépassent nos compétences. Par conséquent, nous estimons que, d'un côté, les institutions ou représentants français en Macédoine sont suffisamment bien implantés et particulièrement actifs sur le sol macédonien mais qu'ils sont également bien mis en valeur et soutenus ou promus par des acteurs macédoniens de l'enseignement et de l'apprentissage de la langue et de la culture françaises, lesquels de leur côté estiment qu'ils ne sont pas suffisamment bien reconnus malgré leurs nombreuses actions et activités de promotion de la Francophonie. Quels sont les principaux acteurs et quels sont leurs plans stratégiques?

\section{Comment est représentée la France en Macédoine du Nord}

\subsection{La Francophonie en Macédoine du Nord}

Il faut noter que la Macédoine est devenue membre observateur de l'Organisation Internationale de la Francophonie au Sommet de Hanoï en 1997, puis membre associé au sommet de Moncton en 1999 et finalement membre à part entière au Sommet de Bucarest le 28 septembre 2006. Ceci est un pas important pour la Macédoine, un moment de reconnaissance aux yeux du monde francophone, mais également un engagement constant dans l'intégration et l'utilisation du français dans l'éducation ainsi que dans la communication internationale. 
Cependant, les relations culturelles entre la France et la Macédoine, sont beaucoup plus anciennes et remontent institutionnellement à 1854 lorsque la France ouvre un premier consulat à Bitola qui était à l'époque encore sous domination ottomane. La tradition perdurant, la nomination, le 25 octobre 1995, d'un consul honoraire, Kaliopa Krivašija Stilinovik, sous l'autorité du consulat général de France à Skopje, puis, la réouverture de l'agence consulaire de Bitola, le 12 juin 1996, par Philippe Seguin, président de l'Assemblée Nationale en présence du premier ambassadeur de France en République de Macédoine, Patrick Chrismant, prouve la forte implication de la ville de Bitola dans les relations franco-culturelles, ainsi qu' au « renforcement et au développement des liens institutionnels, économiques, culturels et scientifiques avec la France» ${ }^{24}$. À part cela, les principaux instruments actuels de cette coopération culturelle sont constitués par l'Institut français de Skopje, ouvert en 1974, par l'Alliance française de Bitola inaugurée en 2000 ainsi que par celle de Tetovo créée en 2001.

Cette coopération est visible grâce à des services qui sont offerts par ces mêmes institutions françaises dans le pays-hôte (médiathèque, bibliothèque, centre de ressources pour les professeurs de français, centre de langue française) mais également, et comme l'indique le site de l'Ambassade de France en Macédoine, « par une participation active et une immersion dans la vie culturelle du pays $»^{25}$.

Ces trois institutions françaises en partenariat avec des institutions locales réalisent des activités diverses de promotion de la langue et de la culture françaises tels le Festival du film français de Skopje, comme celui de la ville de Bitola, des activités d'animations francophones (conférences, expositions, spectacles de théâtre, etc.) ou des projets de coopération culturelle dans le domaine du patrimoine ${ }^{26}$.

D'ailleurs, les actions ou activités de ces institutions découlent d'un plan stratégique qui leur est adressé chaque année par le ministère des Affaires étrangères français, lequel doit prendre en compte les évolutions intérieures du pays pour son rapprochement européen. Les actions principales à l'ordre sont dernièrement :

- La Jeunesse et de la société civile. L'action de la France s'appuie ici particulièrement sur l'office régional de coopération des jeunes et l'attraction des élites ;

- La Francophonie en essayant d'enrayer le déclin du français en Macédoine par une coopération bilatérale. Pour l'OIF par la reprise du programme visant à soutenir les cours de français

\footnotetext{
${ }^{24} \mathrm{https}: / / \mathrm{mk}$.ambafrance.org/L-agence-Consulaire-de-France-a

${ }^{25} \mathrm{https}$ ://mk.ambafrance.org/Presentation, 1138

${ }^{26} \mathrm{https}: / / \mathrm{mk}$.ambafrance.org/Presentation, 1138
} 
des fonctionnaires et pour l'AUF : installer un partenariat avec l'université « Saints Cyrille et Méthode », l'Université d'État de Tetovo, l'Université de tourisme de Skopje, ainsi que l'université "Saint Clément d'Ohrid », par la promotion des études en France (Campus France) et l'appui à la mobilité en Europe ;

- Le Sport et le tourisme vert qui devient une question politique. Comme Paris a été élue hôte des jeux olympiques et paralympiques de 2024, l'IFS et le SCAC inscrit cet événement à venir dans son dialogue avec les partenaires macédoniens et participera à sa promotion à travers de nombreuses activités (cinéma, littérature, livre, langue, photo, et sportrencontres sportives FR-MK). La langue française étant une des langues officielles du comité international olympique sera mis à l'honneur ;

- Communiquer mieux et plus qui se décline pour l'IFS par des actions de visibilité de l'IFS, par une meilleure présence sur les médias TV-radio et sur les réseaux sociaux, une meilleure signalétique extérieure des locaux de l'IFS, par la modernisation du site internet, et de nouvelles pratiques dans le marketing des cours de français ;

- La Coopération administrative, gouvernance, justice et état de droit : les actions de coopération bilatérale portent sur l'état de droit, la bonne gouvernance, la justice, la capacité administrative et les droits de l'homme. Le ministère de l'intégration européenne en Macédoine du Nord porte des réformes prioritaires sur l'énergie, les transports, la francophonie et le tourisme et vise à valoriser l'expertise française et à créer une relation toujours plus forte entre ces différents secteurs de coopération de la délégation de l'UE.

Mais toutes ces actions dépendent d'un facteur commun qui est la connaissance de la langue française ou l'apprentissage de celle-ci dans le pays-hôte qui d'ailleurs remonte à des siècles.

\section{La langue française en Macédoine}

\subsection{Historique de l'apprentissage de la langue française}

Dans la monographie d'Irina Babamova et de Snežana Petrova (BABAMOVA, PETROVA 2016 : 18-22) nous apprenons que l'apprentissage de la langue et de la littérature françaises dans les écoles sur le territoire de la Macédoine remonte au XIXe siècle, par l'ouverture d'écoles françaises et de pensions au sein de missions religieuses à Thessalonique, Yenidže-Vardar, Bitola, Kruševo et autres grâce à des instituteurs macédoniens tels Dimitar Miladinov, Goce Delčev. D'ailleurs on estime que : 
«[...] plus de 10.000 élèves ont appris le français dans les écoles françaises, dont $65 \%$ de Macédoniens et $35 \%$ d'autres groupes ethniques : Juifs, Turcs, Valaques, Albanais, Serbes et autres. La majorité des élèves étaient de Bitola et des environs, mais il y en avait aussi de Kičevo, Resen, Tikveš et Veles. [...] Avec la diffusion de la langue française et la culture, se développaient l'esprit français, les réalisations dans la production, la technologie, l'art, la mode et plus encore. A Bitola, sous l'influence de la mode française, sera adopté un style particulier de robe appelé à la franga » (КРСТЕВСКИ, 1999 : 319) ${ }^{27}$.

$\mathrm{Au}$ cours des années, la langue française, parallèlement au russe, représentait l'une des langues étrangères les plus étudiées à ce niveau d'enseignement et jusqu'aux années 60 du XXe siècle, elle est la première langue étrangère pour le plus grand nombre d'élèves du primaire et du secondaire, devant le russe, l'anglais, et l'allemand. L'enseignement du français prend différentes formes avec le temps :

- Enseignement précoce du français,

lequel a débuté au Centre de langues étrangères de Skopje formé en 1954 puis transformé en 1965 ; au Jardin d'enfants francophone, inauguré en 2000 ; puis à celui du Dr. Judith et Dr. Joseph à Skopje en 2010. Il ne faut pas oublier de mentionner la mise en place du projet «PRECOCE »-Apprentissage précoce de la langue française depuis 2003, et la formation de classes à enseignement intégré du français dans le primaire en R. de Macédoine.

\section{- Enseignement bilingue dans le secondaire,}

le projet de sections bilingues franco-macédoniennes s'est finalisé par l'ouverture de la première classe franco-macédonienne à Negotino en 1997 et a été suivi par 5 autres sections à Bitola (le lycée municipal « Josip Broz Tito »), à Kumanono (le lycée municipal «Goce Delčev »), à Skopje (les lycées « Orce Nikolov » et « Rade Jovčevski-Korčagin ») et une classe francoalbanaise à Tetovo (lycée municipal « Kiril Pejčinović »). La langue française y est enseignée comme langue vivante 1 (LV1).

\section{- Enseignement supérieur,}

Juste après la libération, en 1946, s'est formée la première institution scientifique d'enseignement supérieur, la Faculté de philosophie, qui en son sein accueille, entre autres, un Département de philologie romane, en tant que premier département

\footnotetext{
${ }^{27}$ „Се смета дека[...] преку 10.000 ученици го изучиле францускиот јазик во француските училишта од кои $65 \%$ биле Македонци, а $35 \%$ од другите етнички групи: Евреи, Турци, Власи, Албанци, Срби и др. Повеќето од учениците биле од Битола и околните места, но имало и од Кичево, Ресен,Тиквеш и Велес. [...] Со ширењето на францускиот јазик и култура, се ширел и францускиот дух, постигањата во производството, техниката, уметноста, модата и др. Под влијание на француската мода во Битола се создава посебен стил на облекување наречена а ла франга“" Texte traduit en français par Irina Babamova et Snežana Petrova, auteurs de la monographie (BABAMOVA, PETROVA 2016 : 23).
} 
de langues étrangères, avec des études de langue et littérature françaises ${ }^{28}$. Au fil du temps, la Faculté de philologie se forme pour se distinguer de la Faculté de philosophie, et l'activité du Département s'y développe pour se transformer en Département de langues et littérature romanes englobant l'enseignement de la langue italienne (en 1959), puis de la langue roumaine (en 1970), espagnole (en 1981) et portugaise (en 2007) mais également la traduction vers le macédonien et inversement (en 1985). La Faculté de philologie crée une Division pour l'enseignement des langues étrangères dans des facultés non philologiques de l'Université « Saints Cyrille et Méthode » et la langue française est également enseignée dans d'autres universités de la Macédoine en tant que langue optionnelle et/ou de spécialité. Mais, avec l'application de la réforme de Bologne et principalement du système européen de crédits, l'enseignement de la langue se maintient difficilement dans les curricula. Malgré cela, des collaborations avec des Universités françaises se sont développées, sans oublier que l'Université « Saints Cyrille et Méthode » puis l'Université «Saint Clément d'Ohrid » deviennent membres de l'Agence Universitaire pour la Francophonie (AUF), ce qui assure une visibilité plus accrue de la langue et de la culture françaises.

\subsection{L'enseignement/apprentissage de la langue française (états des lieux actuels dans les écoles)}

La situation dans laquelle se trouve l'enseignement de la culture et de la langue françaises en Macédoine depuis une petite décennie devient périlleuse et même alarmante.

Rappelons qu'actuellement et selon les lois et principes en vigueur, le français est enseigné à l'école primaire en tant que seconde langue étrangère et cela à partir de la $6^{\mathrm{e}}$ classe, la première langue étrangère étant l'anglais, matière obligatoire depuis 2007 qui est enseignée depuis la $1^{\text {ère }}$ classe.

La seconde langue étrangère est également obligatoire, cependant il y a un choix à faire entre différentes langues données en apprentissage (le français, l'allemand, le russe et l'italien depuis peu), choix fait par les élèves ou plus exactement par les parents ou le directeur de l'établissement et, si l'on remonte plus encore dans la hiérarchie, par le maire de la ville et sur décret par le ministre de l'éducation et des sciences de Macédoine du Nord.

Dans le secondaire, il n'y a pas de choix en ce qui concernel'apprentissage de la seconde langue étrangère car il est en continuité par rapport au primaire. Ainsi, l'apprentissage de la langue étrangère dans le primaire se prolonge au lycée pour atteindre le niveau B1/B2 à la fin des études du secondaire.

Quelles sont les causes de cette diminution d'effectifs écoliers comme celui du cadre enseignant? Pourquoi cette perte d'intérêt pour le français ?

\footnotetext{
${ }^{28}$ Il faut mentionner que dès 1924, le Département de langue et littérature françaises fonctionne au sein de la Faculté de philosophie de Skopje mais comme une branche de la Faculté de philosophie de Belgrade (ПАВЛОВИК', М. 2002 : 29).
} 
Ayant pris en compte la relativisation des relations culturelles entre la France et la Macédoine, les collaborations, jumelages, politiques culturelles etc., ces dernières années, malgré les actions entreprises en faveur d'une relance de l'apprentissage du français par les établissements scolaires à tous les niveaux, par de nombreux acteurs, la situation est telle que le français est de moins en moins présent sur le terrain, et tend même à disparaître des programmes, ce qui entraîne une démotivation visible des professeurs de français qui commencent à perdre tout intérêt de prendre part à des actions et activités promotionnelles du français.

Parallèlement à cette situation épineuse pour le français entrent en scénario depuis peu trois événements qui travaillent en sa défaveur :

- le phénomène démographique de baisse de la natalité, ce qui fait que les classes qui devaient compter entre 24 et 34 élèves passent maintenant à 20 élèves et dans certains cas à moins de 10 élèves ${ }^{29}$;

- les tendances actuelles d'immigration en Allemagne de la jeunesse macédonienne qui est attirée par une promesse d'un emploi plus rémunéré et d'une situation sociale meilleure ;

- l'introduction de l'apprentissage de l'italien dans les écoles primaires.

La situation est devenue si pesante que l'Association des professeurs de français de le RMN s'est lancée dans une offensive plus visible. Ainsi, fin septembre 2019, directement au ministre de l'éducation et des sciences, Arber Ademi, puis le 30 janvier au Représentant personnel du Président de la République de Macédoine du Nord auprès de l'OIF, Pajo Avirovic, mais également avant ce dernier, par voie électronique, au Premier ministre, Zoran Zaev, l'Association a discuté et mis en évidence l'état des lieux de l'enseignement de la langue française par une enquête menée dans les 390 établissements scolaires publics (primaire et secondaire) de Macédoine. Cette enquête a révélé entre autres :

- des remplacements illicites de l'enseignement du français par celui de l'allemand dans un bon nombre d'établissements secondaires suite à la demande imposante des parents d'élèves et souvent en cours d'année scolaire;

- une représentation inadéquate de la deuxième langue étrangère et particulièrement du français (matière obligatoire et non pas facultative);

- une perte du nombre de cours et même d'emploi des cadres enseignants.

\footnotetext{
${ }^{29}$ Selon le site officiel du ministère de l'éducation et des sciences de la R. de Macédoine du Nord, in http://mon.gov.mk/images/Закон_за_средното_образование07.pdf, p. 14/67, article 28, le nombre d'écoliers par classe dans les établissements scolaires publics ne doit pas être inférieur à 25 et ne doit pas être supérieur à 34 .
} 
En complément de l'enquête, l'Association a également donné quelques propositions ou possibles réflexions/demandes comme le fait que :

- Le système éducatif devrait prévoir un enseignement des langues étrangères dans les écoles de façon équilibrée et non de façon arbitraire. De la sorte seront entretenues les accords de collaboration et de partenariat entre les deux pays que sont la France et la Macédoine. Il faut comprendre que les capacités langagières font partie aujourd'hui des leviers sociétaux, économiques et professionnels. Et comme le souligne Corinne Weber : « le français fait donc partie aujourd'hui des langues fédératrices (avec l'espagnol et l'allemand) d'une Europe identitaire » (WEBER 2007 : 15), ce qui sous-entend que l'apprentissage de plusieurs langues étrangères (dont le français) offre, comme nous le fait remarquer Christiane Buisseret, plus de possibilité de mobilité, de rencontres et d'échanges scolaires et que la connaissance des langues et des cultures permet de tisser des liens, des ponts, des passerelles entre les jeunes, entre les peuples (BUISSERET 2012 : 4);

- Le choix de la deuxième langue étrangère dans les écoles primaires en tant que matière obligatoire devrait se faire dépendamment $\mathrm{du}$ personnel enseignant existant. Ce dernier doit être protégé des solutions arbitraires actuelles ou futures qui pourraient être envisagées par les structures administratives.

- Dans le cas contraire, le cadre enseignant doit être soit maintenu dans l'établissement mais redéployé vers une autre activité, soit lui être proposé une requalification professionnelle (sur fonds publics);

- Dans la mesure où la deuxième langue étrangère est obligatoire, il convient d'autoriser l'ouverture de nouvelles classes ou le maintien de classes avec un nombre d'élèves réduit ou de groupes plus restreint sachant que la démographie est en baisse donc il y a moins d'élèves dans les établissements scolaires ;

- En ce qui concerne le choix de la seconde langue étrangère, il doit $\mathrm{y}$ avoir des règles clairement définies. Il est possible d'accepter ou d'accommoder la pratique déjà établie par les États voisins d'Albanie, de Grèce, mais également d'Arménie, de Moldavie et du Kosovo, avec un apprentissage du français à 30\%, 30\% pour l'allemand et $40 \%$ pour les autres ;

- Finalement, étant donné que le choix des parents d'apprendre l'allemand est plus que catégorique et exclusif, il serait souhaitable de proposer l'apprentissage de l'allemand dès la première année (selon le système éducatif macédonien) ou en classe de CE1 et donc de pouvoir choisir entre l'anglais et l'allemand comme première 
langue étrangère, puis que le français, le russe ou l'italien soient enseignés à partir de la 6ème année en tant que seconde langue étrangère. De cette façon, tout le monde serait satisfait.

\section{En guise de conclusion}

Notre recherche sur les relations culturo-éducatives entre la Macédoine du Nord et la France a mis en valeur certains faits et démarches positifs comme certains inconvénients et désavantages.

Ainsi les institutions culturelles nationales en France comme les institutions culturelles nationales en Macédoine sont nombreuses mais la présence française en Macédoine est bien plus marquante et visible, sa promotion est plus évidente par rapport à la Macédoine en France. S'agit-il ici d'un problème de politiques culturelles ? Ou de visées plus politisées ou intéressées ? Un Centre culturel macédonien, des galeries d'exposition, des instituts avec un enseignement du macédonien plus nombreux dans toute la France serait vraiment les bienvenus. Ceci offrirait une plus grande visibilité de la culture de la Macédoine du Nord. Certes, le budget du ministère de la culture macédonien n'est pas le même que celui du ministère français, et du coté macédonien, des efforts concrets doivent se faire en ce qui concerne la pérennisation de l'enseignement du français pour que celui-ci ne disparaisse totalement des programmes scolaires. À ce propos la solution au problème consiste à apporter un changement statutaire par un appui politique envers la langue française. La Macédoine est membre à part entière de l'Organisation internationale de la francophonie depuis septembre 2006, ce qui signifie que celle-ci a des obligations politiques vis-à-vis de cette même organisation et vis-à-vis de la France en tant que partenaire stratégique sur la voie de l'adhésion à l'Union européenne.

\section{Bibliographie}

DJIAN 2005 : DJIAN, Jean-Michel. La Politique culturelle, la fin d'un mythe. Paris : Gallimard, 2005.

BABAMOVA, PETROVA 2016: BABAMOVA Irina, PETROVA Snezana. Le français en République de Macédoine. (vu au travers les actions éducatives et culturelles). Skopje : Faculté de philologie « Blaže Koneski », Université « Saints Cyrille et Méthode », 2016.

BUISSERET 2012 : BUISSERET, Christiane. « Editorial. Mais que diable vont-ils faire... dans tous ces congrès ? ». Le français dans le mille. Sortir des frontières. $\mathrm{n}^{\circ} 234$ (2012) : 3-5. 
DRAGIĆEVIĆ ŠEŠIĆ, 2015 : DRAGIĆEVIĆ ŠEŠIĆ, Milena. Vers les Nouvelles politiques culturelles. Les pratiques interculturelles engagées. Belgrade : Maison d'édition CLIO, Université des arts à Belgrade, Association Marcel Hicter, Bruxelles, 2015.

KRSTEVSKI 1999: КРСТЕВСКИАлександар,Изучувањена францускиот јазик во Битола во минатото“ во Македонско-француски врски, Зборник на трудови поднесени на научниот собир одржан на 12-13 јуни 1998г. Битола, Друштво за наука и уметност-Битола, Друштво за француски јазик и култура-Битола, Битола, 1999.

PETROVSKA : PETROVSKA, Ivana. La coopération décentralisée entre la région Normandie et la République de Macédoine. Brochure. Skopje, s.d.

WARESQUIEL 2001 : WARESQUIEL, Emmanuel (dir.). Dictionnaire es politiques culturelles de la France depuis 1959. Paris : CNRS EditionsLarousse-Bordas/Her, 2001.

WEBER 2007 : WEBER, Corinne. " Cartographie de la situation du FLE ». Le français dans le monde, recherches et application, Formation initiale en français langue étrangère : actualité et perspectives, $\mathrm{n}^{\circ} 41$ numéro spécial (janvier 2007) : 14-24.

Снежана Ж. Петрова

\section{КУЛТУРНО-ОБРАЗОВНЕ ВЕЗЕ ИЗМЕЪУ СЕВЕРНЕ МАКЕДОНИЈЕ И ФРАНЦУСКЕ}

Културолошке и образовне везе између Истока и Запада или, прецизније, између Северне Македоније и Француске, датирају одавно. Оне су у мањој или већој мери постојане, у мањој или већој мери видљиве, у мањој или већој мери признате, у мањој или већој мери озакоњене. Притом, успостављају их и одржавају институционални и у основи лични фактори који одређују важност и видљивост језика и културе обеју земаља.

Наш рад се заснива на истраживању које ће се конкретизовати у форми извештаја о актуелним македонским надлежним институцијама у Француској, као и о француским надлежним институцијама у Северној Македонији, експозеа о њиховим услугама и сарадњама, сведочења о њиховом делању и о ангажовању на културолошком и образовном нивоу, као и о присутности и видљивости француског језика и културе унутар македонских образовних установа. Овај рад, дакле, има за циљ да буде сведочење о билатералним односима две земље, али и да истовремено представи евентуалне тежње и идеје о одржавању сарадње.

Кључне речи: културолошке везе, институције, учење француског језика и културе, Француска, Северна Македонија 